\title{
A New Approach to the Chemistry of Gold
}

\author{
N. P. Finkelstein and R. D. Hancock \\ National Institute for Metallurgy, Johannesburg, South Africa
}

cepts, a better understanding of the chemistry of gold can be achieved. In this paper graphic displays of the tendency for the metal to oxidise and for its ions to form complexes are introduced, and it is shown that they allow the observed behaviour to be viewed in a way that is not only rational but is also very simple and potentially useful.

The past two decades have seen a renaissance in the study of inorganic chemistry. Great strides have been made in the understanding of bonding and of the principles by which the properties of moleculestheir colour, their stability, their reactivity-are governed, and sophisticated theoretical and experimental methods of interpretation and study have been developed. Perhaps it is this very sophistication that has concealed from the average practising industrial or analytical chemist that this renaissance has not only led to considerable extensions in the scope of inorganic chemistry-to the relatively exotic organometallics, for instance, and to such curiosities as the compounds of the rare gases-but it has also brought with it more rational ways of approaching the chemistry of the more mundane, more familiar compounds with which the bulk of practising chemists still find themselves concerned. The seemingly unrelated facts can now be understood and rationalised, and the subject can be made to lose its dry-as-dust aspect.

In the present paper we shall take a new look at the chemistry of gold and its simple compounds, and demonstrate how the use of two relatively modern techniques can bring new understanding and practical benefits.

\section{Gold-the Noble Metal}

The nobleness of gold is at once the most practised cliche about the metal, and the key to both its romance and its major down-to-earth industrial uses. To come to grips with the substance behind the cliché, let us consider gold in its most common environment -at ambient temperature, in more-or-less wet air.

In order to react, the metal must oxidise, say:

$$
\mathrm{Au} \rightarrow \mathrm{Au}^{+}+\mathrm{e}
$$

The tendency for this reaction (i.e. the reduction potential) is given by the Nernst equation:

$$
\mathrm{E}=\mathrm{E}^{\circ}-2.3 \frac{\mathrm{RT}}{\mathrm{F}} \log \frac{\{\mathrm{Au}\}}{\left\{\mathrm{Au}^{+}\right\}},
$$

where $\mathbf{R}$ is the gas constant, $\mathbf{F}$ the faraday, $\mathbf{T}$ the absolute temperature, and $\mathrm{E}^{\circ}$ the standard reduction potential for the reaction $(=1.67 \mathrm{~V}$ on the hydrogen scale). If the activity of the metal, $\{\mathrm{Au}\}$, is taken as unity, and if the activity of the dissolved species $\left\{\mathrm{Au}^{+}\right\}$ is assumed to be equal to its molar concentration [Au], we have at $25^{\circ} \mathrm{C}$ :

$$
E=1.67+0.0591 \log \left[\mathrm{Au}^{+}\right]
$$

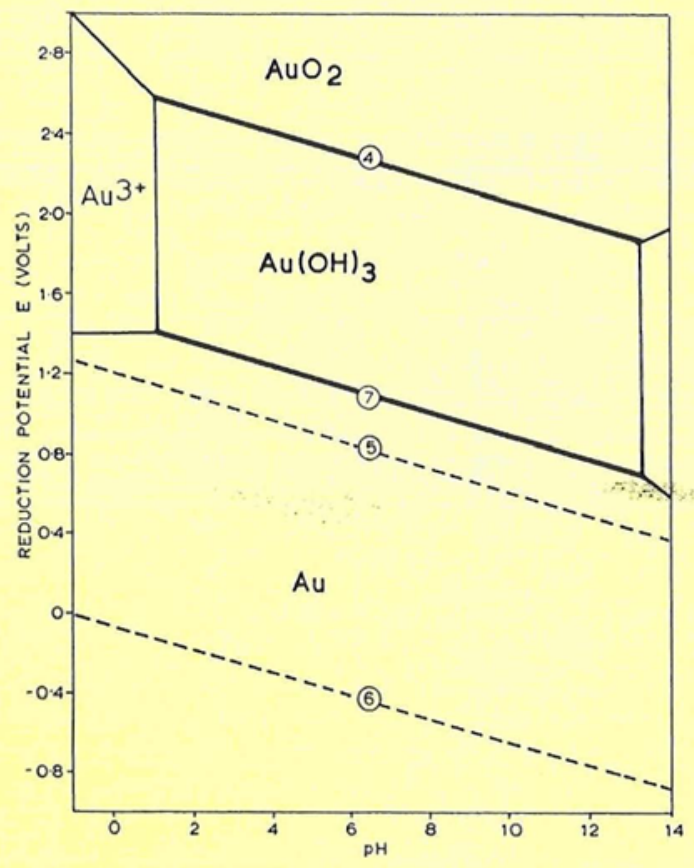

Fig. 1 Peurbaix diagram for the syotem $\mathrm{Au}_{-} \mathrm{H}_{2} \mathrm{O}$ at $25^{\circ} \mathrm{C}$. The concentrations of all gold species is $10^{-4} \mathrm{M}$. This shows that in the absence of complexing reagents gold should only exist as the metal within the domain of atability of water (i.e. in the area bounded by lines 5 and 6) 
For the alternative oxidation:

$$
\mathrm{Au} \rightarrow \mathrm{Au}^{\mathrm{s}+}+3 \mathrm{e}^{-} \text {, }
$$

we can write similarly

$$
\mathrm{E}=1.498+0.0197 \log \left[\mathrm{Au}^{8+}\right] \text {, }
$$

In oxidising, the metal may also interact with its environment:

$$
\begin{array}{lr}
\mathrm{Au}+3 \mathrm{H}_{2} \mathrm{O} \leftrightarrows \mathrm{Au}(\mathrm{OH})_{3}+3 \mathrm{H}^{+}+3 e & \text { III } \\
\mathrm{E}=1.457-0.0591 \mathrm{pH} & 3 \\
\mathrm{Au}(\mathrm{OH})_{3} \leftrightarrows \mathrm{AuO}_{2}+\mathrm{H}_{2} \mathrm{O}+\mathrm{H}^{+}+\mathrm{e} & \mathrm{IV} \\
\mathrm{E}=2.630-0.0591 \mathrm{pH} & 4
\end{array}
$$

These reactions can take place only if sufficiently powerful oxidants are present in the environment. The following redox couples can be considered:

$$
\begin{aligned}
& 2 \mathrm{H}_{2} \mathrm{O} \rightrightarrows \mathrm{O}_{8}+4 \mathrm{H}^{+}+4 \mathrm{e} \quad \mathrm{V} \\
& \mathrm{E}=1.228-0.0591 \mathrm{pH}+0.0147 \mathrm{Po}_{2} \quad 5 \\
& 2 \mathrm{H}_{2} \mathrm{O}+2 \mathrm{e} \Rightarrow 2 \mathrm{OH}^{-}+\mathrm{H}_{2} \quad \text { VI } \\
& \mathrm{E}=0.0591 \mathrm{pH}-0.0295 \log \mathrm{P}_{\mathrm{H}_{2}} \quad 6
\end{aligned}
$$

Thus far we have proceeded by classical means. When we come to make use of these relationships and to decide which reactions take precedence and which species are stable under particular conditions, we find that the classical methods of comparing reaction-by-reaction are tedious and confusing.

It is helpful to express the system graphically according to a plot developed originally by $\mathrm{Dr}$ Marcel Pourbaix, of the Central Belge d'Etude de la Corrosion in Brussels (1). In such a diagram, the equilibrium potential of each couple is plotted against $\mathrm{pH}$ for particular concentrations. Figure 1 shows such a potential-pH diagram for the system $\mathrm{Au}-\mathrm{H}_{2} \mathrm{O}$.* The heavy full lines delineate the regions of predominant stability of solid species which are denoted by bold face type (e.g. $\mathrm{AuO}_{2}$ ); lighter full lines indicate the conditions in which the relevant solid species has a particular solubility, and lighter-faced type (e.g. $\mathrm{Au}^{3+}$ ) is used to denote soluble species. In constructing Figure 1, a concentration of $10^{-4} \mathrm{M}$ has been used throughout. Thus line (7) represents the relationship

$$
\begin{aligned}
& \mathrm{Au}^{3+}+3 \mathrm{H}_{2} \mathrm{O} \leftrightarrows \mathrm{Au}(\mathrm{OH})_{3}+3 \mathrm{H}^{+} \\
& \mathrm{pH}=-\frac{1}{3} \log \mathrm{Au}^{3+}-0.693
\end{aligned}
$$

and indicates the conditions under which auric hydroxide is in equilibrium with $10^{-4} \mathrm{M}$ auric ions.

* For simplicity, some soluble species such as $\mathrm{H}_{3} \mathrm{AuO}_{3}$ and $\mathrm{H}_{2} \mathrm{AuO}_{3}$ - have been neglected, and the domains of relative stability of solution species have been omitted. For a more complete diagram, as well as a comprehensive explanation of the workings of such diagrams, the reader is referred to the original work of Pourbaix.
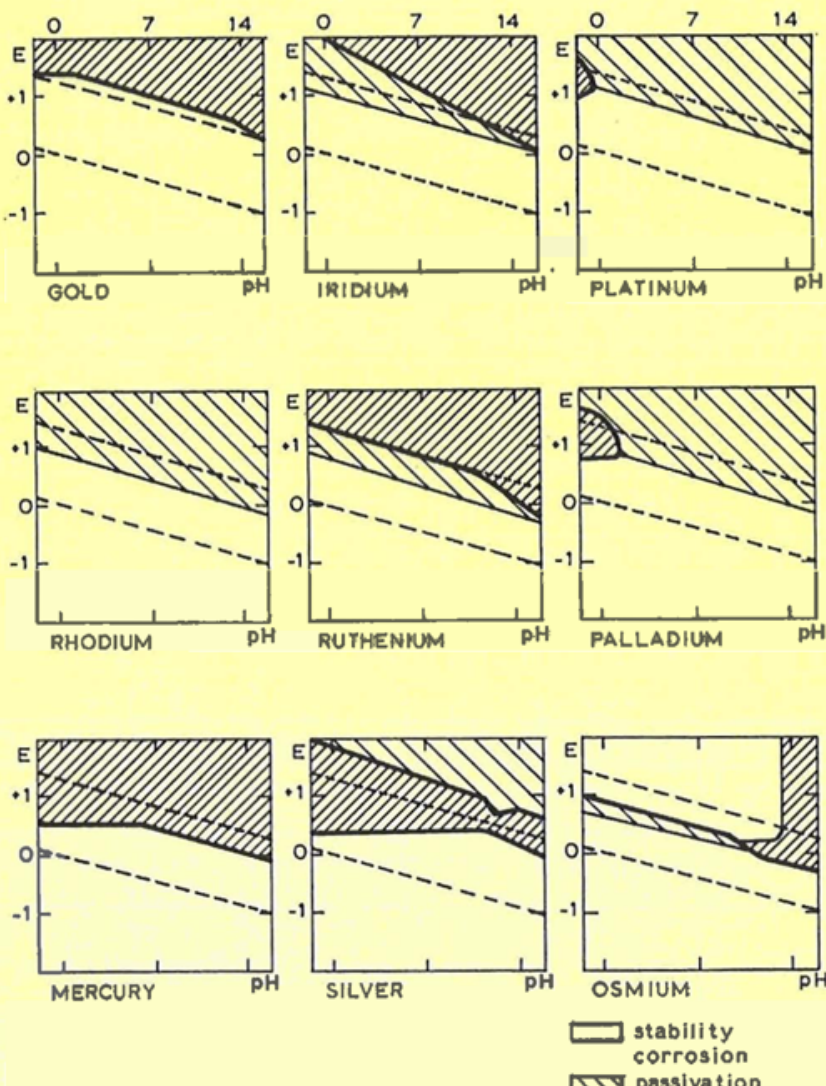

Fig. 2 Pourbaix diagrams for the most noble metals, placed in order of decreasing nobility. With the exception of gold, all metals form compounds that are stable in the presence of water. In some instances, and under some conditions. these compounds form passivating films that protect the metal from extensive corrosion. The domain of stability of water is bounded by the dashed lines.

Figure 1 summarises the chemistry of the $\mathrm{Au}-\mathrm{H}_{2} \mathrm{O}$ system neatly and concisely. Its meaning becomes clear once we note that lines 5 and 6 are the boundaries of the domain of stability of liquid water. At: potentials lower than those of line 6 , water is reduced to hydrogen; at potentials greater than those of line 5, water is oxidised to oxygen. It is clear from Figure 1 that the oxidised forms of gold exist only at potentials significantly greater than those of line 5 . Thus water will reduce each of the oxidised forms shown-the solid $\mathrm{AuO}_{2}$ and $\mathrm{Au}(\mathrm{OH})_{3}$ and the dissolved $\mathrm{Au}^{3+}$ and $\mathrm{HAuO}_{3}{ }^{2}-$-to the metal at all $\mathrm{pH}$ values; and thus gold cannot be oxidised by dissolved oxygen and is not attacked by strong acids and alkalis. This analysis gives quantitative meaning to the "noble" property of the metal, and makes it clear how it arises.

Potential-pH diagrams offer a convenient method of comparing the characteristics of one metal with those of another. Figure 2 shows such diagrams for several 


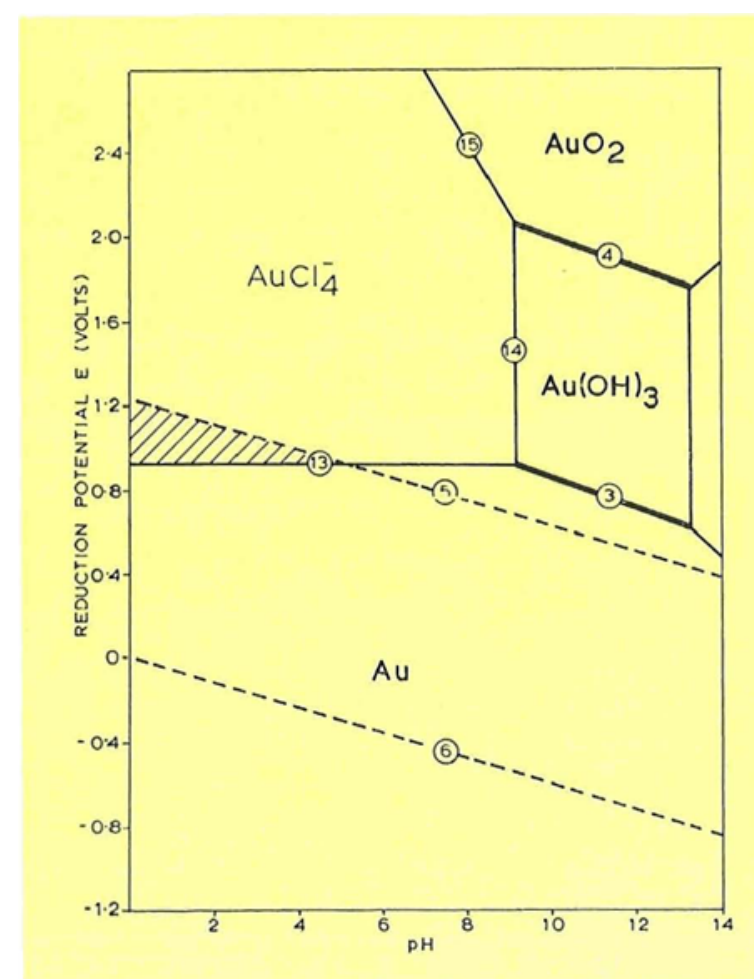

Fig. 3 Pourbaix diagram for the system $\mathrm{Au}-\mathrm{H}_{2} \mathrm{O}$ $\mathrm{Cl}^{-}$at $25^{\circ} \mathrm{C}$. $[\mathrm{Au}(\mathrm{III})]=10^{-2} \mathrm{M}$. $\left[\mathrm{Cl}^{-}\right]=2 \mathrm{M}$. $\mathrm{PO}_{2}=$ $P_{\mathbf{H}_{2}}=1$ atm. By comparison with Figure 1 it can be seen that in the presence of chloride the domains in which $\mathrm{Au}(\mathrm{OH})_{3}$ and $\mathrm{AuO}_{2}$ are the most stable species are reduced, and that there is a region (shown shaded) in which the metal is not the most stable species

other noble and a single base metal in pure aqueous solution at ambient temperature. It can be seen that the extent of the domains of stability of the elemental forms vary from metal to metal. None of these metals is stable throughout the domains of stability of water. There can be no doubt that gold, like Shakespeare's Caesar, is "the noblest . . o of them all".

Instructive though these diagrams undoubtedly are, they do not represent the whole chemistry of the metal. In the first place, they are purely thermodynamic representations and take no account of the kinetic properties of the systems. Thus, although according to energetic considerations dissolved oxygen can oxidise platinum to $\mathrm{PtO}_{2}$, in practice kinetic barriers prevent this reaction from proceeding to any significant extent.

In the second place, the systems that we have considered up to now have embraced only the ligands $\mathrm{H}_{2} \mathrm{O}$ and $\mathrm{OH}^{-}$. It is now well established that the ionic $\mathrm{Au}^{+}$and $\mathrm{Au}^{3+}$ do not exist free in solution, as is implied by equations such as I and II above, but will always form complexes with available ligands. In pure water, they will aquate to form the respective aquo ions. Thus reactions I and II are more correctly written in terms of the ions $\mathrm{Au}\left(\mathrm{H}_{2} \mathrm{O}\right)_{2}{ }^{+}$and $\mathrm{Au}\left(\mathrm{H}_{2} \mathrm{O}\right)_{4}{ }^{3+}$. If a stronger ligand than $\mathrm{H}_{2} \mathrm{O}$ is present, e.g. chloride, the equilibria

$$
\begin{aligned}
& \mathrm{Au}\left(\mathrm{H}_{2} \mathrm{O}\right)_{2}{ }^{+}+2 \mathrm{Cl}^{-} \leftrightarrows \mathrm{AuCl}_{2}^{-}+2 \mathrm{H}_{2} \mathrm{O} \text { and } \\
& \mathrm{Au}\left(\mathrm{H}_{2} \mathrm{O}\right)_{4}{ }^{3+}+4 \mathrm{Cl}^{-} \leftrightarrows \mathrm{AuCl}_{4}^{-}+4 \mathrm{H}_{2} \mathrm{O}
\end{aligned}
$$

will be established. As a result, reactions I and II will reach equilibrium further to the right, the reduction potentials will be reduced and the metal will be rendered more easily oxidised. Similarly, the positions of all other equilibria involving $\mathrm{Au}^{+}$ (i.e. $\left.\mathrm{Au}\left(\mathrm{H}_{2} \mathrm{O}\right)_{2}{ }^{+}\right)$and $\mathrm{Au}^{3+}$ (i.e. $\mathrm{Au}\left(\mathrm{H}_{2} \mathrm{O}\right)_{4}{ }^{3+}$ ) will be changed.

Figure 3 summarises the effect of the addition of chloride ion to the $\mathrm{Au}-\mathrm{H}_{2} \mathrm{O}$ system. In the top lefthand quarter of the diagram there has been imposed a region in which the most stable and predominant species is $\mathrm{AuCl}_{4}$-. The extent of this domain varies directly with the concentration of gold in solution. Figure 3 is drawn for $\mathrm{Cl}^{-}=2 \mathrm{M}$ and $[\mathrm{Au}(\mathrm{III})]=$ $10^{-2} \mathrm{M}$.

It is important to note that a part of the domain of stability of $\mathrm{AuCl}_{4}^{-}$(shown shaded) falls within the region of stability of water. Therefore, in the presence of chloride ion, gold can exist in an oxidised form in contact with water under acid conditions.

If a stronger ligand than chloride were present, the domain of stability of the oxidised species would be correspondingly increased. For example, in the presence of $\mathrm{CN}^{-}$, a $\mathrm{pH}$-potential diagram (2) shows that the species $\mathrm{Au}(\mathrm{CN})_{2}-$ is stable over nearly the whole of the region of stability of water.

\section{Complexes of Gold}

It is apparent that the ability of gold to form complexes is of the greatest importance in determining the behaviour of the metal in solution. A glance at any chemistry text shows that there exists a large number of gold complexes with a complete spectrum of stabilities. It is obvious that this bewildering mass of detail requires to be rationalised if the chemistry of gold is to be understood and if the practising chemist is to be able to utilise it to full advantage.

A first useful generalisation which can be made about the stability of gold complexes relates to the nature of the ligand donor atom, i.e. the atom in the ligand which is bound directly to the gold. Both $\mathrm{Au}(\mathrm{I})$ and $\mathrm{Au}(\mathrm{III})$ are B-type metal ions. This means that the stability of their complexes tends to decrease with increasing electronegativity of the ligand donor atom. In A-type metal ions the opposite effect is found, with stability increasing with electronegativity of the donor atom. B-type metal ion behaviour is localised in a pyramid based roughly on gold in the periodic table: 


$\begin{array}{lllllllllll}\text { A-type } & & & & & & & & & & \\ \ldots & \mathrm{Cr} & \mathrm{Mn} & \mathrm{Fe} & \mathrm{Co} & \mathrm{Ni} & \mathrm{Cu}(\mathrm{II}) & \mathrm{Zn} & \mathrm{Ga} & \mathrm{Ge} & \ldots \\ \ldots & \mathrm{Mo} & \mathrm{Tc} & \mathrm{Ru} & \mathrm{Rh} & \mathrm{Pd} & \mathrm{Ag} & \mathrm{Cd} & \mathrm{In} & \mathrm{Sn} & \ldots \\ \ldots & \mathrm{W} & \mathrm{Re} & \mathrm{Os} & \mathrm{Ir} & \mathrm{Pt} & \mathrm{Au} & \mathrm{Hg} & \mathrm{Tl} & \mathrm{Pb} & \ldots\end{array}$

B-type metal ions

The B-type metal ion behaviour of $\mathrm{Au}(\mathrm{I})$ and $\mathrm{Au}$ (III) thus leads to stability orders such as $\mathrm{I}^{-}>\mathrm{Br}^{-}>\mathrm{Cl}^{-}$ $>\mathrm{F}^{-}$, where the order of electronegativities is $\mathrm{F}^{-}>\mathrm{Cl}^{-}>\mathrm{Br}^{-}>\mathrm{I}^{-}$. More generally, we note that electronegativity is a periodic property of the elements. For elements that would possibly form complexes with gold we thus have:

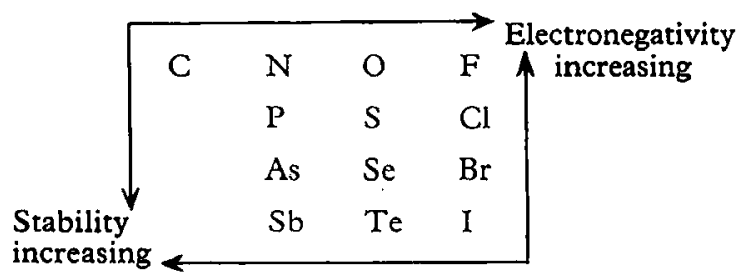

This scheme, then, accounts for the stability order noted for halogen complexes above. It also accounts for stability orders such as $S e=\mathrm{C}\left(\mathrm{NH}_{2}\right)_{2}>$ $S=\mathrm{C}\left(\mathrm{NH}_{2}\right)_{2}>O=\mathrm{C}\left(\mathrm{NH}_{2}\right)_{2}$ (the donor atom is italicised in each case), or $\mathrm{CN}^{-}>\mathrm{NH}_{3}>\mathrm{H}_{2} \mathrm{O}$, and suggests why gold tellurides and the aurostibnite $\left(\mathrm{AuSb}_{2}\right)$ are stable enough to be found in nature.

Useful as the above general rule is, for more accurate prediction of the stability of gold complexes a different approach is required. It has been found (2) that, when the standard reduction potentials of analogous complexes of two similar metal ions with the same electronic configuration are plotted against each other, a linear relationship results. In Figure 4 is seen the relationship between the $\mathrm{E}^{\circ}$ values for the reaction:

$$
M L_{8}(a q)+e \rightarrow M(s)+2 L
$$

where $M=A u(I)$ and $A g(I)$. (Au(I) and $A g(I)$ each have ten $d$-electrons in their outer orbitals being known as $d^{10}$ ions). The particular usefulness of such a relationship is that, whereas standard reduction potential data for $\mathrm{Au}(\mathrm{I})$ are difficult to determine and very sparse in the literature, for $\mathrm{Ag}(\mathrm{I})$ the determination is fairly easy, and the literature abounds with data on the standard reduction potentials of $\operatorname{Ag}(\mathrm{I}) \mathrm{com}$ plexes. The linear relationship in Figure 4 can be expressed in the form of an equation:

$$
\mathrm{E}_{\mathrm{Au}(\mathrm{l})}^{\circ}=1.77 \mathrm{E}_{\mathrm{AB}(\mathrm{I})}^{\circ}+0.26 \mathrm{~V}
$$

This equation may now be used to calculate $A u(I)$ standard reduction potentials from the $\mathrm{Ag}(\mathrm{I})$ values.

Fig. $4 \mathbf{E}^{\circ} / \mathbf{E}^{\circ}$ diagram for complexes of $\mathrm{Au}(\mathrm{I})$ and $\mathrm{Ag}(\mathrm{I})$. More negative values of $\mathbf{E}^{\circ}$ indicate higher stabilities in the complex. It can be seen that the stabilities of corresponding complexes of the two ions are linearly related

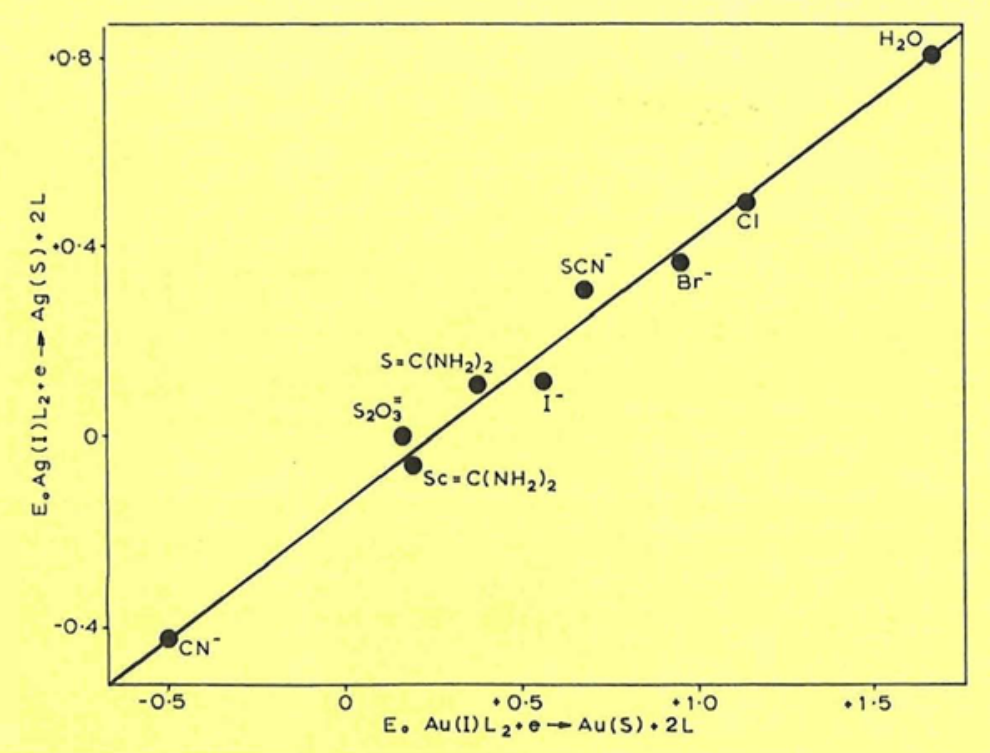




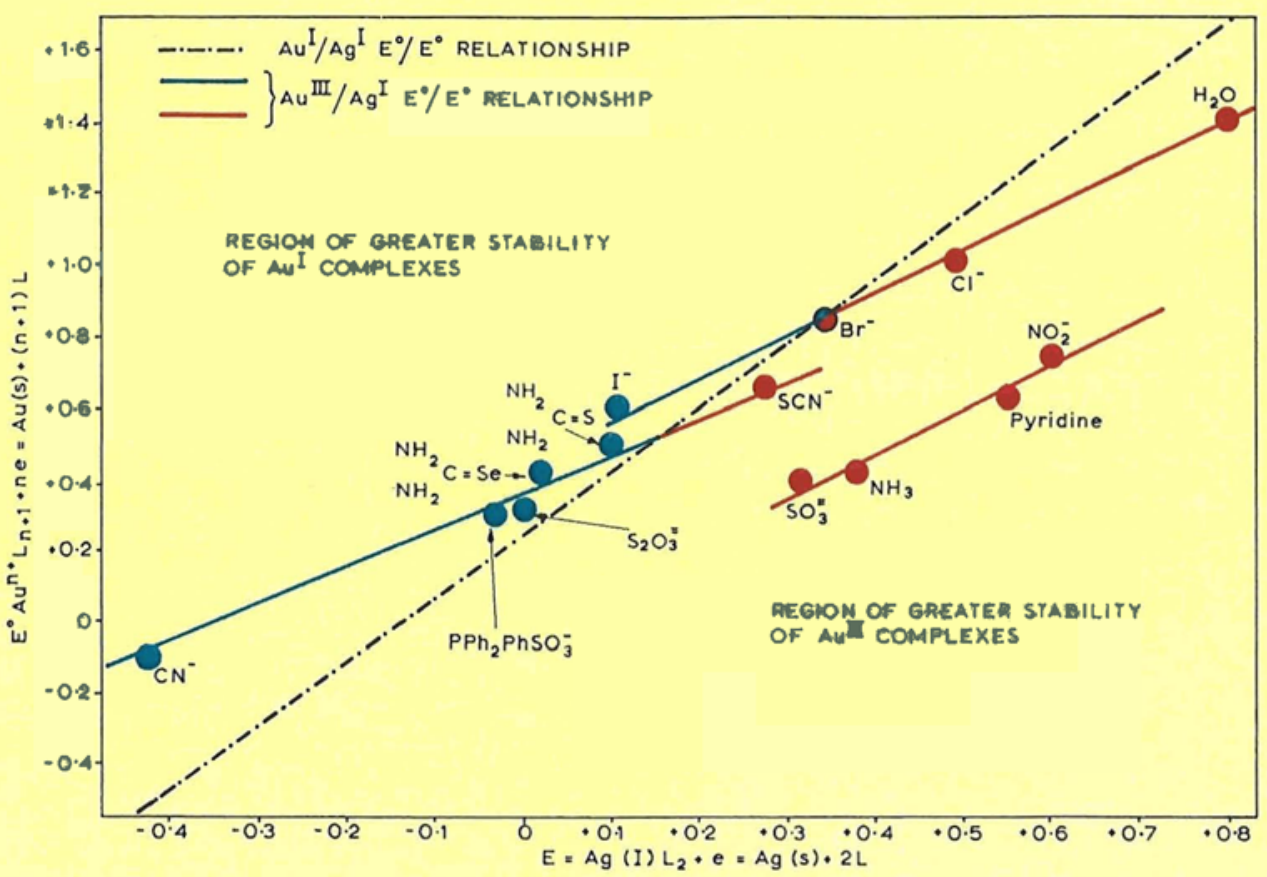

Fig. $5 \mathrm{E}^{\circ} / \mathrm{E}^{\circ}$ diagram comparing the stabilities of complexes of $\mathrm{Au}(\mathrm{III}), \mathrm{Au}(\mathrm{I})$ and $\mathrm{Ag}(\mathrm{I})$. This shows clearly which ligands prefer to form auric complexes and which favour the aurous state

A potential of great interest as far as $\mathrm{Au}(\mathrm{I})$ complexes are concerned is the standard reduction potential of the $\mathrm{Au}^{+}$aquo ion quoted earlier in this paper. The free $\mathrm{Au}^{+}$aquo ion is so unstable that it does not exist to any appreciable extent in water, so that direct measurement of its $\mathrm{E}^{\circ}$ is impossible. However, it may be calculated, using equation 8 and $\mathrm{E}^{\circ}$ for the $\mathrm{Ag}^{+}$ aquo ion $(+0.799 \mathrm{~V})$, to be $+1.67 \mathrm{~V}$. Thus we have been able to draw up the potential-pH diagrams for $\mathrm{Au}(\mathrm{I})$ in water, although it has not been possible to measure the relevant potentials directly.

Data for $\mathrm{Au}$ (III) complexes are even more scarce than for $\mathrm{Au}(\mathrm{I})$. We can however, draw up $\mathrm{E}^{\circ} / \mathrm{E}^{\circ}$ diagrams for $\mathrm{Au}$ (III) using the electronically analogous ions $\mathrm{Pd}(\mathrm{II})$ and $\mathrm{Pt}(\mathrm{II})$, since $\mathrm{Au}(\mathrm{III}), \mathrm{Pt}(\mathrm{II})$ and $\mathrm{Pd}(\mathrm{II})$ are all ions with a $\mathrm{d}^{8}$ electronic configuration. These relationships can be expressed in the form of equations:

$$
\begin{aligned}
& \mathrm{E}_{\mathrm{Au}(\mathrm{III})}^{\circ}=1.05 \mathrm{E}_{\mathrm{Pd}(\mathrm{II})}^{\circ}+0.35 \mathrm{~V} \\
& \mathrm{E}_{\mathrm{Au}(\mathrm{III})}^{\circ}=0.93 \mathrm{E}_{\mathrm{Pt}(\mathrm{II})}^{\circ}+0.32 \mathrm{~V}
\end{aligned}
$$

Using these, a mean value for the standard reduction potential of the $\mathrm{Au}^{3+}$ aquo ion of $+1.39 \mathrm{~V}$ is calculated.

If we draw up the $\mathrm{Au}$ (III) $/ \mathrm{Ag}$ (I) $\mathrm{E}^{\circ} / \mathrm{E}^{\circ}$ diagram (Figure 5) we see that a simple linear relationship does not result. Instead, three separate linear sections are found, each containing three different types of ligand. The most important feature of this diagram is that on the left occur the less electronegative, or soft as they are sometimes described, donor atoms (e.g. $\mathrm{S}, \mathrm{Se}, \mathrm{P}$, etc.), while on the sections on the right occur the more electronegative, or hard, donor atoms (e.g. $\mathrm{N}, \mathrm{O}, \mathrm{F}, \mathrm{Cl}$, etc.) This break reflects the different requirements for stability in complex formation, soft ligands forming more stable complexes with metal ions of low valency, (e.g. $\mathrm{Au}(\mathrm{I})$, $\mathrm{Ag}(\mathrm{I})$ ), while hard ligands prefer metal ions of higher valency (e.g. $A u(I I I))$. If we draw in the $A u(I)$ $\mathrm{E}^{\circ} / \mathrm{E}^{\circ}$ diagram (dotted line), it is seen that the points for the Au(III) complexes with soft ligands lie above the $\mathrm{Au}(\mathrm{I})$ line. This indicates that complexes of $\mathrm{Au}$ (III) with soft ligands will be easily reduced to the $\mathrm{Au}(\mathrm{I})$ state. Thus, for example, $\mathrm{Au}(\mathrm{CN})_{2}{ }^{-}$and $\mathrm{Au}\left(\mathrm{S}=\mathrm{C}\left(\mathrm{NH}_{2}\right)_{2}\right)_{2}{ }^{+}$are the species formed in the leaching of gold with $\mathrm{CN}^{-}$or thiourea, since the $\mathrm{Au}$ (III) species will tend to be reduced if it is formed at all.

On the other hand, the hard ligands form complexes with $\mathrm{Au}(\mathrm{III})$ which fall below the $\mathrm{Au}(\mathrm{I}) / \mathrm{Ag}(\mathrm{I})$ line, and here the converse is true. Thus, with $\mathrm{Cl}^{-}$, the stable species is the trivalent $\mathrm{AuCl}_{4}^{-}$, and $\mathrm{AuCl}_{2}{ }^{-}$ will tend to disproportionate as

$$
3 \mathrm{AuCl}_{2}^{-} \leftrightarrows \mathrm{AuCl}_{4}^{-}+2 \mathrm{Au}(\mathrm{s})+2 \mathrm{Cl}^{-}
$$

One of the surprising predictions made by Figure 5 concerns the reduction of $\mathrm{AuCl}_{4}^{-}$to metallic gold 
using $\mathrm{SO}_{2}$. This dissolves in water to give $\mathrm{SO}_{3}{ }^{2-}$ ions, and it is observed that, when $\mathrm{SO}_{2}$ is bubbled through yellow $\mathrm{AuCl}_{4}^{-}$solutions, the solution goes colourless before precipitating solid $\mathrm{Au}$. One would automatically think that the colourless solution, which is fairly stable when basic, would contain the monovalent complex, $\mathrm{Au}\left(\mathrm{SO}_{3}\right)_{2}{ }^{3-}$, since $\mathrm{Au}(\mathrm{I})$ species tend to be colourless while $\mathrm{Au}$ (III) are more often coloured. However, examination of Figure 5 shows that with $\mathrm{SO}_{3}{ }^{2-}$ the trivalent complex $\mathrm{Au}\left(\mathrm{SO}_{3}\right)_{4}{ }^{5-}$ should be the more stable. In fact the UV spectrum of the gold sulphite solutions contains only peaks characteristic of $\mathrm{Au}$ (III) species, showing that the predictions of the $\mathrm{Au}(\mathrm{III}) / \mathrm{Ag}(\mathrm{I}) \mathrm{E}^{\circ} / \mathrm{E}^{\circ}$ relationship are correct.
In using all these predictions, one should bear in mind, of course, that one is looking at only one side of the coin-that, in addition to the thermodynamics of the situation, there are also the kinetics to be borne in mind. Thus, we may predict that a reaction is thermodynamically possible, but it may happen so slowly as to be of no importance.

\section{Acknowledgement}

This paper is published by permission of the DirectorGeneral, National Institute for Metallurgy.

\section{References}

1 M. J. N. Pourbaix, 'Atlas D'Equilibres Electrochimiques', Gauthier-Villars, Paris, 1963

2 R. D. Hancock and N. P. Finkelstein, Inorg. Nucl. Chem. Letters, $1971, \mathbf{7},(5), 477-484$

\section{The Electrical Resistance of Vanadium-Gold Alloys}

It is now just IIo years since Matthiessen (I) summarised his conclusions on the electrical characteristics of metals and alloys. Their resistance, he suggested, was the sum of a "thermal" resistance, unaffected by the presence of impurities, and of a "temperature independent" resistance caused by the presence of impurities or intentional alloying additions. This beautifully simple idea explained why the alloys of highest electrical resistance also had the lowest temperature coefficients, and precision resistance alloy development was thereby considerably facilitated.

Vanadium increases the resistivity of gold more rapidly than any other single alloying addition, and the primary solid solutions thus formed are strong, ductile, and readily drawn into fine wire. By adding small quantities of palladium to these binary solutions, $\mathrm{Dr}$ F. Sperner of Heraeus (2) has recently developed some very valuable alloys which combine a high resistivity with stability, low thermal e.m.f., and a temperature coefficient of only a few p.p.m. per ${ }^{\circ} \mathrm{C}$. In view of these practical implications, therefore, the results of a recent attempt to interpret the electrical characteristics of vanadium-gold alloys in terms of Matthiessen's original conception become of particular interest.

This work, carried out at the University of Sussex, (3) was part of a continuing programme concerned with the effect of $3 \mathrm{~d}$ transitional impurities upon the resistivity of gold. The alloys investigated contained respectively 2.0 and 0.8 atomic per cent of vanadium, such low concentrations satisfying the requirements of electronic band theory. Resistivity measurements were made at narrow intervals over the temperature range 0.5 to $273 \mathrm{~K}$. The high excess resistivity of the alloys, (i.e. the difference between the resistivity of the pure metal and that of the alloy at the same temperature) was found not to be constant as Matthiessen would have suggested. While moderately steady at temperatures below $50 \mathrm{~K}$, it then began to fall rapidly and almost linearly with rising temperature, thus compensating for the increasing resistivity of the gold and accounting in part for the anomalously low temperature coefficient of these solid solution alloys.

Earlier work on gold alloys containing small quanti- ties of titanium, manganese, iron, cobalt and nickel (4) had shown that the resistivity results could be successfully interpreted in terms of a two band electronic model which allowed the effect of temperature on those factors which cause phonon and impurity scattering to be quantitativly established. Similarly varying coefficients were found to be applicable to vanadium-gold alloys, and were used to calculate the resistivity which could reasonably be caused by alloying effects. These calculated resistivities were very much lower than the total excess resistivities which were measured, and the discrepancies between theoretical and experimental results were found to be roughly proportional to the concentration of vanadium which was present. The authors conclude that alloying effects account for only part of the total resistivity of vanadium-gold alloys, and that departures from Matthiessen's rule increase rapidly and become very significant as the wires warm up to room temperature.

The practical metallurgist might well have expected this conclusion, as all the standard resistance alloys such as Manganin, Constantan, and Nichrome are anomalous in the Matthiessen sense. Their departures from the ideal state are, however, fairly minor. Vanadium-gold alloys deviate from the straight and narrow additive path very strongly indeed, and Ford and his coworkers demonstrate very convincingly that their high electrical resistance can only be partly accounted for by the two-band electronic alloy model. One is left to conclude that some unknown and powerful resistive component resides in these transition metal solutions and that a fuller understanding of the mechanism involved might result in the rapid development of a new generation of electrical resistance alloys.

\section{References}

1 A. Matthiessen and C. Vogt, Trans. Roy. Soc., 1864, 154, 167

2 F. Sperner, Gold Bulletin, 1973, 6, (3), 72

3 P. J. Ford, T. E. Whall and J. W. Loram, 7. Phys, F: Metal Phys., 1974, 4, (2) 225

4 T. E. Whall, P. S. Ford and J. W. Loram, Phys, Rev. B., $1972,6,3501$ 